\title{
Variação e Gramática: colocação de clíticos na bistória do português brasileiro $^{1}$
}

\author{
Variation and Grammar: clitic-placement in the history \\ of Brazilian Portuguese
}

\author{
Zenaide Carneiro \\ Universidade Estadual de Feira de Santana \\ Charlotte Galves \\ Unicamp
}

\begin{abstract}
In private correspondence written in Brazil in the $19^{\text {th }}$ Century, we find a variable clitic-placement in all syntactic contexts. This departs from both modern Brazilian grammar, which generalizes proclisis (cl-V) and classical and modern European grammars, in which the proclisis-enclisis distribution is governed by very strict rules, strongly sensitive to the type of clause in which the clitic pronoun occurs. In this paper, we argue that this variation is the effect of the competition in texts between those three grammars (or I-languages). This competition is associated with change, but we show that, in the case we consider, the direction of change may change throughout time.
\end{abstract}

Keywords

Clitic-placement, History of Brazilian Portuguese, Grammar competition. 


\section{Resumo}

Em correspondências privadas escritas no Brasil durante o século 19, encontramos colocação de clíticos variável em todos os contextos sintáticos. Isso se afasta tanto da gramática brasileira moderna, que generaliza a próclise (cl-V), quanto do português europeu e do português clássico, em que a distribuição entre próclise e ênclise (V-cl) é regida por regras muito estritas, altamente sensíveis ao tipo de oração. Neste artigo, argumentamos que essa variação é o efeito da competição instanciada nos textos entre essas três gramáticas ou Línguas-Internas. Tal competição está associada com a mudança, mas mostramos que, no caso que consideramos, a direção da mudança instanciada pelos textos pode mudar ao longo do tempo.

\section{Palavras-chave}

Colocação de clíticos, História do português brasileiro, Competição de gramáticas. 


\section{Introdução}

este artigo, apresentamos a variação na colocação dos pronomes clíticos ao longo do século 19 no Brasil. Tomamos como base o Corpus de cartas particulares constituído por Carneiro (2005), que reúne textos escritos entre 1809 e 1904 por brasileiros, nascidos entre 1724 e 1880, e divididos em dois grupos: "cultos" - ou seja, altamente escolarizados, e "semicultos", ou seja, com um nível de escolarização limitado ao nível primário. Chama a atenção, nesses textos, a grande variação na colocação de clíticos. Como já tinha sido mostrado por Pagotto (1992), em todos os contextos sintáticos, sem exceção, encontramos colocação pré-verbal (próclise) alternando com colocação pósverbal (ênclise). Isso contrasta fortemente com o que se observa no português europeu moderno (doravante PE), em que a distribuição entre ênclise e próclise é regida por regras sintáticas muito estritas. Também se diferencia claramente do português clássico (doravante $\mathrm{PCl}$ ), que só permite a variação ênclise/próclise em alguns contextos. Enfim, também se distingue do que se registra no português brasileiro moderno falado (doravante PB), em que a tendência é generalizar a próclise em todos os contextos. Argumentaremos que a variação encontrada no referido Corpus se deve a uma competição de gramáticas nos textos (KROCH, 1994, 2001). O interesse particular desses dados vem do fato de que, nesse caso, não há somente duas gramáticas em presença, mas três, que correspondem às três vertentes do português mencionadas: $\mathrm{PCl}, \mathrm{PE}$ e PB.

Além da alternância ênclise/próclise, encontramos uma variação na colocação dos clíticos nos grupos verbais, também já observada por Pagotto (1992), que deriva do surgimento, no português falado no Brasil, de novas posições para o pronome: a afixação às formas participiais, e a próclise ao infinitivo. Nesse caso, o PB se distingue tanto da língua clássica quanto do PE, que, em relação a esse fenômeno, se comportam da mesma maneira.

O trabalho está organizado em três partes: na Seção 1, descreveremos a variação encontrada. Na Seção 2, apresentaremos mais detalhadamente as três 
gramáticas em competição. Na Seção 3, enfim, mostraremos como a dinâmica da variação e da mudança pode ser explicada como parte de um processo de competição de gramáticas.

\section{Descrição da variação na colocação de clíticos nas Cartas Brasileiras}

Nesta seção, consideramos separadamente dois aspectos distintos da colocação de clíticos: em primeiro lugar, a variação na posição pré-verbal (próclise) ou pós-verbal (ênclise) do pronome; em segundo lugar, a variação no seu lugar de afixação nos grupos verbais: à forma finita ("subida do clítico") ou à forma não finita ("não subida").

\subsection{Variação ênclise/próclise}

Na apresentação dessa variação, organizamos os dados em relação aos padrões do PCl e do PE, ou seja, classificando-os pelos contextos, que nessas gramáticas são de ênclise obrigatória, de próclise obrigatória, ou de variação. É preciso ressaltar que nesta seção consideramos somente as orações finitas. Mostraremos na seção seguinte que a mesma variação se dá com as formas verbais não finitas.

\section{A. Contextos de ênclise obrigatória em PCl e PE:}

- Verbo em primeira posição absoluta (V1)

(1) a. Abstenho me de outras noticias, pois| por completo as terão com a volta do Ledeira| carta 275 (CARNEIRO, 2005, p. 144).

b. Me entendi com o João Victorino a serca| do seo boi que matarão, e depois disto>| 4r. tudo resolvido trataremos da liqui|dação, me paresse é que o tal sugei=|to não terá com que pague, com quanto| á pesar de ser morador aqui eu| não conheço bem se elle pode pa|gar.| carta 418 (CARNEIRO, 2005, p. 146) 
B. Contextos de variação ênclise/próclise em $\mathrm{PCl}$ (cf. GALVES et al. 2005a) e ênclise obrigatória em PE

- Verbo em segunda posição precedido de sujeito, sintagma preposicional e sintagma adverbial

Sujeito-V

(2)a. Elle pedio me que| renovasse o pedido de reserva a VossaExcelência, neste assumpto, que pode ainda mais comprometter a sua situação|2r. carta 258 (CARNEIRO, 2005, p. 149).

b. Neusinha e eu constristamo-nos| muito com o topico da carta, que VossaExcelência| escreveu a D. Carolina, referindo, que| tivera noticia de nosso casamento,| por intermedio do digno representan-|te de VossaExcelência, |carta 267 (CARNEIRO, 2005, p. 149).

c. Eu me dou por| satisfeito que ahi do Rio| ordenes tudo o que se deve| fazer. carta 63 (CARNEIRO, 2005, p. 149).

d. Osorio me escreveu com data de 2, um| tanto queixoso de lhe mandares officiaes| paisanos e $<$ de $>$ lhe teres suspendido o direito| de dar patentes de comissão, quando elle| estava creando artilheiros para as| baterias novas. carta 49 (CARNEIRO, 2005, p. 149).

\section{Advérbio não modal -V}

(3) a. Hontem encontrei-me, no banco de Santa The-|reza, com o Senhor Franken, que mani-| 2r. 9-1-02| 3|faltou de novo a possibilidade de ser| levada a effeito uma operação externa| para a Bahia, passado como está o passado| agudo da crise Europeia.| carta 253 (CARNEIRO, 2005, p. 149).

b. Hoje lhe escrevi com toda a amizade. carta 59 (Carneiro, 2005, p. 149). 
Sintagmas preposicionais - V

(4) a. Com effeito telegraphei lhe, pedindo socorro| para a Empreza Viação em permanente ameaça de| liquidação forçada pela falta de pagamento dos| juros dos seos debentures.| carta 219 (CARNEIRO, 2005, p. 149).

b. Com a vista lhe| narrarei os pormenores a respeito.| carta 442 (CARNEIRO, 2005, p. 150).

\section{- Verbo em posição inicial em segunda coordenada}

(5) a. Nunca esquece-|rei o que recebi d'esses Senhores;| porem, como o homem que se involui| nesta mizeravel pulitica, não| tem sentimentos, eu, coro a face,| e abrolhes os dentes.| carta 337 (CARNEIRO, 2005, p. 153).

b. Tive oprazer de receber sua apreci|avel cartinha, eofellicito por seu bem| estar e daExcelentissima comadre emeninos| aquem, com o devido acatamento,| Saudo - carta 193 (CARNEIRO, 2005, p. 154).

- Verbo precedido de orações dependentes reduzidas e orações desenvolvidas

(6) a. Se és meu amigo, faze me o| obsequio de quando qualquer coisa| te desagradar dizer-m'o a mim,| como eu te faço, e não a| terceiros, que por fim| se riem de nós dois.| carta 63 (CARNEIRO, 2005, p. 154).

b. Se eu tiver tempo me darei a honra| de visitar a sua capital antes de regressar| aos Estados Unidos.| carta 280 (CARNEIRO, 2005, p. 154).

- Verbo precedido de complementos diretos

(7) a. Saude paz e tranquillidade desejo-lhe em companhia| da Excelentissima, a quem respeitosamente visito -|carta 321 (CARNEIRO, 2005, p. 157).

b. Saúde lhe appeteço, e disposto ao| que for de seu serviço, sou| De VossaExcelência| Respeitoso affetuoso e obrigadissimo| carta 76 (CARNEIRO, 2005, p. 157). 
- Verbo precedido de constituintes retomados pelo clítico

(8) a. Na tua carta a mim fallas me de regressar áo| Brasil, e na que escreveste a Gomes e elle me leo, só| lhe fallas de doença de insonnia e falta de ape-|tite. Oh! Senhor Ferraz! o que he isto para quem ja| passou meio seculo?| carta 82 (CARNEIRO, 2005, p. 158).

b. Este desgosto elle o teve, e veio da parte de um| homem que em 1890 subia as escadas da casa| de um chefe, chamando-o protector, que tinha| a custo arracado a licença para a sua can|didatura de deputado do Marechal Deodoro, que| ao ouvir a pretensão desse candidado, transfe-|riu-o como militar para a guarnição da| fronteira do Rio Grande do Sul, carta 294 (CARNEIRO, 2005, p. 158).

\section{Contextos de próclise obrigatória em PCl e PE}

- Verbo precedido de partícula focalizadora e quantificadora, sujeitos quantificados e com focalizadores explícitos.

(9) a. Todos envião lhe a-|braços e recommendações. Lourdes| e Thereza, digo Felicia, envião beijos| e pedem ben-çãos.| carta 306 (CARNEIRO, 2005, p. 156).

b. Todos me fallão| bem delle, carta 34 (CARNEIRO, 2005, p. 157).

\section{- Orações negativas}

(10) a. Oportador vai com or|dem de puchar, náo demore-o|2r. Que com minha Comadre passe sem altera|ção - Disponha do|Primo compadre amigo do Coração| Antonio Ferreira| carta, 348 (CARNEIRO, 2005, p. 162).

b. Não me nego de forma al-|guma ao seu serviço, más| sinto aparecer estes desgostos| entre amigos, e mórmente| em um logar como o Timbó,| que precisamos trabalhar |3r. muito para combater os adver-|sarios, que alli dispoem de| todos os elementos. carta 370 (CARNEIRO, 2005, p. 162). 


\section{- Orações relativas}

(11) a. Hontem passei hor|rivelmente atacado por uma depressão| na região precordial, que durou-me| até as 5 horas da tarde. carta 132 (CARNEIRO, 2005, p. 164).

b. Poucos dias depois d'aqui chegar fui acommettido de uma| febre renittente de carater typhico que me| perseguio durante 28 dias e me deixou em mesmo| estado de depauperamento e fraqueza. carta 219 (CARNEIRO, 2005, p. 164).

\section{- Orações subordinadas}

(12) a. Recommendaste me que interviesse no novo| contracto de fornecimento. Mas quando chegou-|me o teu Aviso, ja o contracto novo me| era communicado pelo Osorio. carta 49 (CARNEIRO, 2005, p. 164).

b. Saó 11 horas da manha quando| me aparto dos amigos por teren| elle de fazer feira. Ficaráo| lavradas 11 copias eprontas| as 5 que faltáo Manuel Ferreira e Manuel que|3v.dáo contacarta 341 (CARNEIRO, 2005).

- Orações interrogativas diversas e expressões fixas

(13) a. Sua carta de 16 d'este, em resposta| as minhas de 18 e 25 do passado e de 5 e-| 11 deste, me foi entregue no dia 22-| V. não se persuadia que o pôvo do Con-|selheiro recuava perante a força Fede-|ral, embóra fosse elle em numero-| muito inferior? Já desenganou-se? carta 371 (CARNEIRO, 2005, p. 166).

b. Valha me Deos! carta 63 (CARNEIRO, 2005, p. 63).

c. Onde a hei de metter? ! carta 63 (CARNEIRO, 2005, p. 63).

d. O Céo lhe dê consolações.| carta 199 (CARNEIRO, 2005, p. 189).

Os exemplos apresentados mostram que em todos os contextos, sem exceção, as Cartas Brasileiras apresentam variação entre a posição enclítica e proclítica. 


\subsection{Variação subida/não subida nos grupos verbais}

Nos grupos verbais, observamos tanto o padrão brasileiro, de não subida do clítico ao auxiliar quanto o padrão europeu, de subida. ${ }^{2} \mathrm{O}$ primeiro está ilustrado em (14-18) onde o clítico está afixado de maneira inequívoca ao particípio passado. Em (14) vemos um advérbio ocorrendo entre o auxiliar e o clítico. Em (15-18) a presença de elementos que forçam a próclise ao auxiliar em PE e PCl, como já, não, muito, que não têm efeito sobre a posição do clítico que continua proclítico ao auxiliar.

(14) Li sua correspondencia e a ousada resposta do taturfo João Dantas,| apresentou-se n'este escripto como homem sem macula, porem conto| que Vossa Excelência o esmagará e para o faser não será preciso discrever todas| essas [...]mazellas! porque em toda sua vida tem por artimanhas se apossa-| do de uma grande parte da fortuna dos que o tem acompanhado| e locupletando-se dos dinheiros dos cofres publicos!: carta 415 (CARNEIRO, 2005, p. 188). ( $\left.\mathrm{PCl}^{*}, \mathrm{PE}^{*}, \mathrm{PBok}\right)$

(15) Não fosse merecedor, mas|como aeleição estava perto que| meprestaria aesta depois| que lhevisse por que não sei| seo ceo ricentimento he deforma| que eu oacompanho em [to]|do centido Digame como ver|dadeiro amigo com franque|za pois ja tenho lhedito que so V. eso| V. emais ninguem. Apareço| breve elhe trazer odinheiro do Mel|quides pois não oaxei nas canas| esim navarzia Salgada| carta 403 (CARNEIRO, 2005, p. 188). (PCl*, PE*, PBok)

(16) Não te-|nho lhe escripto supondo ja| se ter regressado para o Regalo,| e Camuciatá onde devo mandar| Potamio visital-o, a Baronesa e os| Primos. carta 433 (CARNEIRO, 2005, p. 188). ( $\left.\mathrm{PCl}^{*}, \mathrm{PE}^{*}, \mathrm{PBok}\right)$

(17) Muito tenho medado com o Tenente e continuo elle| me dice que lhe presa e que meo compadre he| muito Amigo do Padrinho e tio delle que| mora na esplanada. carta 485 (CARNEIRO, 2005, p. 124). (PCl*, EP*, PBok)

(18) Sua Excelência respondeu me -| que ja haviam lhe escrito da Bahia sobre este assump|to, que faria o que pudesse; mas que n'essas 
nomeaçoens| se praticantes costuma regular - se pelas propostas,| que vem de lá - conforme o resultado dos concursos_| carta, 197 (CARNEIRO, 2005). (PCl*, PE*, PBok)

Todavia também encontramos frases em que o clítico inequivocamente está afixado ao auxiliar, em próclise, no exemplo (19), ou em ênclise, no exemplo (20), em que o sujeito ocorre entre o clítico e o particípio.

(19) Nada tenho oque di-|zer da Policia que comprio seo de-| 2r.ver, eo Tenente metem tractado per-|feitamente bem como tanto nao me-|reço, i assim té o ultimo dos solda-|dos. Carta, 427 (CARNEIRO, 2005). (PClok, EP*, PB*)

(20) Tem-me isto cau-|sado grande sentimento já pelo aconte-|cimento ser na minha Freguesia, já porque a| nubente he minha Afilhada, que muito estimo| porém talves, que este máo proceder remo|vesse outros Summamente repprovados segun-|do o que agora tenho ouvido diser.| carta 207 (CARNEIRO, 2005). (PClok, EPok, PB*)

Enfim, uma grande parte dos casos são ambíguos, uma vez que as duas colocações são compatíveis com a ordem linear, como em (21).

(21) Como, porem, deixaste sem resposta as minhas| primeiras cartas, a certeza de que, por esse meio,| não tevi noticias directas tuas, tem me feito| contacto com o que sei pelos amigos. carta 272 (CARNEIRO, 2005, p. 188).

É interessante notar que o clítico, quando não se move para o auxiliar, pode aparecer à direita da forma não finita, ou seja, enclítico a essa, como exemplos em (22). Essa ordem, totalmente ausente do português europeu, mostra que na afixação do clítico à forma não finita, como nos outros contextos, a ênclise alterna com a próclise.

(22) a. O novo Juiz de direito vai indo;|2r. muito Viannista - tem trata $=\mid \mathbf{d o}$-me bem, e até aqui| vai indo. Fiquei sciente so=|bre Urpia. Tenho estado com| seus vaqueiros, e disem-me| que há serios prejuisos. -|carta 328 (CARNEIRO, 2005, p. 183).

b. Não pude ir n'esse| dia e até hoje cumprimental-o, por| ter saidome um leicenço no pesco-|ço, junto a nuca, temi viajar. Foi| o 
Cezar e os outros parentes. Já o-| tinha visto quando veio até junto| da Vila e regressou-se a Queimadas.| carta 422 (CARNEIRO, 2005, p. 184).

Os exemplos em (23) ilustram esse mesmo fato com o verbo no infinitivo. Note-se que, no português clássico e no português europeu moderno, de novo, tal variação não existe, a ênclise sendo a única opção.

(23) a. Elle, como mandei dizer-lhe, compra e não vende deben-|tures. Todos os possuidores de| maior somma destes, estão con|vencidos, como elle e o Ludolf, de que a empreza é de grande| futuro. carta 305 (CARNEIRO, 2005, p. 195).

b. Quero ainda uma vez lhe| agradecer as boas e generosas| palavras com que hontem| eloquentemente saudou-me| em nome do povo bahiano!| carta 166 (CARNEIRO, 2005, p. 188).

Enfim, aparecem casos em que há duas cópias do clítico. O clítico é visto em ambas as posições, junto ao verbo finito e junto ao verbo não finito, como exemplificado em (24):

(24) P.S. se lhe for po çi|vel mande me nomiar me $\mid 1^{\circ}$ Juis de Pas| carta 476 (CARNEIRO, 2005, p. 184).

É importante notar que a variação descrita aqui não é um caso isolado. Um estudo recente realizado em textos literários produzidos em Santa Catarina na mesma época aponta para os mesmos fenômenos (cf. MARTINS, 2009).

Na próxima seção, introduziremos a noção de competição de gramáticas (KROCH, 1994, 2001), e definiremos as gramáticas em presença. Em seguida, mostraremos e analisaremos a dinâmica desses fenômenos ao longo do tempo.

\section{As gramáticas em competição}

No quadro teórico da gramática gerativa, uma dicotomia fundamental é a de Língua-Interna, ou Língua-I, e Língua-Externa, ou Língua-E. (Cf. CHOMSKY, 1986). A língua-I é definida como o estado final de uma capacidade inata para a linguagem ou gramática universal, resultante da marcação de parâmetros, durante a aquisição da linguagem. A língua-E é o conjunto dos enunciados produzidos pela Língua-I em situações de uso. Uma característica fundamental 
da Teoria da Gramática Gerativa é definir seu objeto como sendo a Língua-I (ou gramática) e não a Língua-E.

Em linguística histórica, em que não temos acesso aos falantes nativos para elicitar julgamentos de aceitabilidade, só podemos atingir a língua-I dos autores a partir da língua-E instanciada nos textos escritos. Uma importante contribuição nesse sentido se deve ao modelo de competição de gramáticas de Kroch $(1994,2001)$. A ideia básica que sustenta esse modelo é que os fragmentos de língua-E que observamos nos textos podem ser produzidos por mais de uma língua-I. Entretanto, a coexistência de línguas-I nos textos é instável e corresponde a um processo de mudança em que uma gramática acaba substituindo a outra. Uma vantagem desse modelo é que ele permite reconciliar a ideia de que a mudança épor natureza brusca, uma vez que ela se dá no processo de aquisição da língua materna, por alguma falha na transmissão das gramáticas (cf. LIGHTFOOT, 1999; ROBERTS, 2007), mas ela se realiza de maneira gradual nos textos. Isso pode ser entendido como a pressão da norma ou da tradição sobre o processo de escrita, em que o vernacular demora a impor-se. Uma outra vantagem reside no fato de que a variação encontrada nos textos, que corresponde a valores paramétricos variáveis, não põe em xeque uma teoria que define gramáticas de maneira categórica, em que os valores atribuídos aos parâmetros são mutuamente incompatíveis no interior de um único sistema, uma vez que tal variação se deve à coexistência nesses textos de mais de uma gramática.

Os documentos estudados por Carneiro (2005) oferecem um caso muito rico e complexo, mas bastante esclarecedor da natureza do fenômeno, de competição de gramáticas. A seguir, vamos mostrar que eles são o produto não só de duas, mas de três gramáticas em competição. Ao lado do vernacular que aparece ainda timidamente nos textos - mais, como seria de esperar, nos semicultos do que nos cultos - vemos o reflexo da competição que se instaurou em Portugal no século anterior (cf. GALVES et al., 2005a), entre o PCl e o PE. Essa tensão entre três sistemas distintos explica não só a coexistência de enunciados aparentemente incompatíveis, mas as particularidades da dinâmica da evolução da colocação de clíticos tal como ela aparece ao longo dos textos. O século 19, com efeito, apresenta uma tendência inesperada quando se compara com o que aconteceu mais tarde no século 20: o aumento da ênclise em orações em que o verbo não ocupa a primeira posição. Essa mudança, que mais tarde fracassará, ${ }^{3}$ seria incompreensível fora de um modelo de competição de gramáticas. 
Na próxima seção, definiremos de maneira mais precisa as três gramáticas instanciadas nas Cartas Brasileiras.

\subsection{As gramáticas em competição nas Cartas Brasileiras}

\section{GRAMÁTICA 1. Português Clássico (PCl)}

O português clássico se caracteriza por definir, de maneira inequívoca, contextos de ênclise obrigatória, de próclise obrigatória, e de variação ênclise/ próclise (cf. GALVES et al., 2005a).

- Ênclise obrigatória (V-cl) - em sentenças iniciadas por verbos (V1):

(25) Apartava-o da mulher, dos filhos, dos vassallos, dos amigos, e de tudo o que amava, ou de quem era amado na vida. (VIEIRA, 1608, Corpus Tycho Brahe).

-Próclise obrigatória (cl V)-em orações negativas, em orações dependentes, e em orações afirmativas não dependentes com o verbo precedido (c-comandado) por quantificadores, focalizadores, palavras interrogativas e certos advérbios:

(26) a. O nó do papo não se quer grande, nem a cerviz aspera por ossos. (FRANCISCO DE HOLANDA, 1510, Corpus Tycho Brahe).

b. Se vos achais em disposição belígera, armemos esta gente; (FRANCISCO MANUEL DE MELO, 1608, Corpus Tycho Brahe).

c. E alguns se spantarão de eu tanto encomendar esta pintura, mas eu nada d'isso me spantarei. (FRANCISCODE HOLANDA, 1510, Corpus Tycho Brahe).

d. O que passou nella, sò ella o poderia dizer, mas nem ella poderia. (MARIA DO CÉU, 1658, Corpus Tycho Brahe).

e. e quem nos ha de presidir neste conselho? (MANUEL DA COSTA, 1601, Corpus Tycho Brahe).

f. Assim o disse ao senhor arcebispo da Baia, que me faz muita mercê; (ANTONIO DAS CHAGAS, 1631, Corpus Tycho Brahe). 
- Variação Próclise/Ênclise

No que diz respeito à variação ênclise/próclise, Galves et al. (2005a) distinguem dois tipos distintos de contextos. No que as autoras denominam Contexto de variação I, o verbo é imediatamente precedido seja pelo NP sujeito, seja por um advérbio (não proclisador) ou ainda um sintagma preposicional, como ilustrado a seguir:

\section{Sujeito-V:}

(27) a. Eu corro-me de dizer o que padeço (MELO, 1608, Corpus Tycho Brahe).

b. Ele me disse que pasmava como lhe abastava o que tinha (SOUSA, 1554, Corpus Tycho Brahe).

\section{Advérbio-V:}

(28) a. Depois sucedeo-lhe o Mirão, seu sobrinho, ... (COUTO, 1542, Corpus Tycho Brahe).

b. Sábado passado vos mandei um papel de engaços (MELO, 1608, Corpus Tycho Brahe).

\section{Sintagma preposicional-V:}

(29) a. Em troca disto, ofereço-lhe da parte de Inglaterra defesa de tôdas as suas colónias e ... (ALORNA, 1750, Corpus Tycho Brahe).

b. Com este aviso lhe foi juntamente infundida notícia dos excessos que entre estas duas súbditas suas passavam. (BERNARDES, 1644, Corpus Tycho Brahe).

Nesses contextos, a próclise é amplamente majoritária, com uma frequência de pelo menos $80 \%$ na maioria dos textos. ${ }^{4} \mathrm{O}$ Contexto de variação II corresponde a construções em que a frequência da ênclise é muito maior, e a variação entre os autores é muito mais ampla. Essas construções são de dois tipos, com uma oração dependente precedendo imediatamente o verbo, como o exemplo (30) e nas segundas coordenadas, com o verbo seguindo imediatamente a conjunção, como em (31). Esses dois contextos são ilustrados, a seguir: 
(30) a. Para os começar a render, amimou-os com donativos, língua a todas as Nações não menos inteligível, que grata. (A. BARROS, 1675, Corpus Tycho Brahe).

b. Vendo-o um Cónego no adro daquela antiga Sé lhe disse: De quem sois meu menino? (A. BARROS, 1675, Corpus Tycho Brahe).

(31) a. Achou-os ditosamente, falou-lhes, e rendeu-os a largarem aquela vida brutal, e virem a ser filhos da Igreja, e vassalos do Império Português. (A. BARROS, 1675, Corpus Tycho Brahe).

b. Durando as persuasões do padre, chegou preparada uma mezinha, e lhe pediram se retirasse. (BERNARDES, 1644, Corpus Tycho Brahe).

No PCl, há muita evidência de que a ênclise é um fenômeno de natureza prosódica associado à posição inicial do verbo na frase entoacional. Além de ser obrigatória somente quando o verbo está em primeira posição absoluta, e ser marginal quando ele está precedido por algum sintagma, encontram-se índices de que, nesse caso, o sintagma pré-verbal pertence a outra frase entoacional. Galves et al. (2005a) apresentam o resultado de um estudo que mostra que, nas construções em que uma oração dependente precede o verbo, existe uma correlação entre o comprimento dessa oração, medido em número de palavras, e a ocorrência da ênclise. Observa-se um aumento significativo desta quando a oração pré-verbal tem mais de nove palavras. Outro argumento encontra-se na frequência muito alta de ênclise nos Sermões do Padre Vieira quando comparado com os autores da sua época. Galves (2003) mostra que todos os casos de ênclise nos Sermões, sem exceção, correspondem a frases em que o verbo é precedido por um tópico de tipo contrastivo, como ilustrado a seguir, em (32):

(32) Elles conheciam-se, como homens, Christo conhecia-os, como Deus. (VIEIRA, 1608, Corpus Tycho Brahe).

O fato de a contrastividade estar associada à presença da ênclise constitui uma evidência suplementar para a sensibilidade desta à prosódia das sentenças, uma vez que os tópicos contrastivos recebem normalmente um contorno entoacional independente do resto da frase. Desse ponto de vista, a alta frequência da ênclise nos Sermões de Vieira se explica pela recorrência da 
expressão do contraste entre termos (Deus e os homens, o juízo final e o juízo da morte, o juízo de Deus e o juízo dos homens, etc.).

Concluímos, portanto, que em $\mathrm{PCl}$ a ênclise ocorre quando o verbo está iniciando um domínio entoacional, seja porque ele é o primeiro elemento absoluto da frase, seja porque o que o precede está numa frase entoacional independente.

GRAMÁTICA 2 - Português europeu moderno (PE)

No PE, os contextos de próclise obrigatória se mantêm iguais aos do $\mathrm{PCl} .^{5}$ No entanto, a ênclise se torna muito mais frequente, uma vez que, não só em contextos em que o verbo está em primeira posição, mas também em todos aqueles que eram variáveis em $\mathrm{PCl}$, a ordem V-cl é obrigatória.

No PE, a distribuição da ênclise e da próclise não pode ser mais derivada de restrições de natureza prosódica, uma vez que, nessa língua, a posição do clítico é definida unicamente com base na sintaxe das orações. Para um determinado contexto, a ênclise é ou bem obrigatória, ou bem impossível. ${ }^{6}$ Em outras palavras, não há mais contextos de variação. São numerosas as análises propostas para essa sintaxe, bastante peculiar, da colocação de clíticos em PE. Seguiremos aqui a análise de Galves e Sândalo (2004, 2009) que argumentam que nessa língua houve uma mudança na natureza do domínio no qual o clítico não pode estar em primeira posição. Não se trata mais de um domínio prosódico, a frase entoacional, mas do domínio sintático - ou 'fase', nos termos de Chomsky (1999) - CP., Galves e Sândalo (2009) formulam assim a restrição que força o clítico a se afixar à direita do verbo:

- Os clíticos não podem ocupar o núcleo mais alto da fase CP.

Essa restrição apreende o fato de que, sempre que algum núcleo mais alto do que aquele que o clítico ocupa é ativado, a próclise é licita. No caso contrário, a ênclise é derivada. ${ }^{9}$

GRAMÁTICA 3 - Português brasileiro moderno (PB)

Apesar de ser marcado por uma variação no uso, em particular na escrita, pode-se dizer que a gramática da colocação de clíticos no PB se caracteriza pela próclise generalizada em todos os contextos, inclusive aqueles em que a ênclise é obrigatória tanto em PCl quanto em PE, ou seja, nas orações V1 - sempre 
enclíticas na história do português europeu. É também o caso das orações V2 não dependentes em que a língua moderna em Portugal generalizou a ênclise. Os exemplos a seguir são extraídos de O Alquimista, de Paulo Coelho (cf. GALVES et al., 2005b, para uma comparação das versões brasileiras e portuguesas dessa obra).

(33) Me chamo Fátima - disse a moça...

(34) Ele me parece mais velho e mais sábio.

(35) quando ele era criança, seu avô lhe dissera ...

(36) E de repente, me pegava pelas mãos...

(37) Depois me ensinou coisas belas

Além disso, o português brasileiro se afasta tanto do $\mathrm{PCl}$ quanto do PE pela colocação pronominal nos grupos verbais, em que os pronomes estão afixados não ao auxiliar finito, mas ao verbo temático, como exemplificado nos exemplos abaixo, também retirados de O Alquimista, em que, apesar de haver um atrator para o clítico à esquerda do verbo finito, ele aparece à esquerda do verbo infinitivo. Vale citar também a "correção" efetuada pelo revisor da edição portuguesa do romance (cf. GALVES et al. 2005b, p. 150). ${ }^{10}$

(38) a. Por que quis me ver? - disse o rapaz (PB)

b. Por que me quis ver? - disse o rapaz (PE)

(39) a. E quando ela foi me mostrar o local exato... (PB)

b. E quando ela me foi mostrar o local exato... (PE)

Exemplos do mesmo fenômeno podem ser encontrados também no Corpus da NURC, onde a frase a seguir mostra de maneira não ambígua que o clítico está afixado ao verbo infinitivo e não ao verbo finito, uma vez que uma locução adverbial ocorre entre o pronome e o verbo finito:

(40) Não posso no momento lhe dar .... 
A gramática do PB se distingue assim por duas importantes características:

i. a ausência da restrição do clítico em primeira posição;

ii. a afixação ao verbo temático mesmo quando este não carrega as marcas de finitude.

Galves et al. (2005b, p. 162) formulam essas duas características da seguinte maneira:

Our proposal is that the different behavior of clitics in EP and PB derives from the interaction of two different properties: a) The category to which clitics syntactically attach: EP clitics are Inflclitics and BP clitics are V-clitics. b) The phonological requirement that forces clitics to be in a non-initial position with respect to some boundary: This requirement is active in EP but not in BP. ${ }^{11}$

Segundo a análise das autoras, duas propriedades distinguem o PB de ambos, o PE e o PCl: uma propriedade de natureza morfo-fonológica que diz respeito à restrição de primeira posição, inativa no PB, ativa no português europeu, tanto moderno quanto clássico, e uma propriedade sintática que define a posição em que os clíticos aparecem na oração. Em português europeu, tanto clássico quanto moderno, eles se afixam ao verbo que carrega a flexão de tempo e concordância. Em português brasileiro, eles ficam junto ao verbo do qual são o complemento, independentemente de esse ser flexionado ou não.

Recapitulando, as diferenças paramétricas entre PCl, PE e PB no que diz respeito à sintaxe dos clíticos podem ser sintetizadas da seguinte maneira:

- Restrição de primeira posição

$$
\begin{array}{lll}
\text { - Restrição de primeira posição } & \text { SIM (PCl/PE) } & \text { NÃO (PB) } \\
\text { - Domínio da restrição } & \text { prosódico (PCl) } & \text { sintático (PE) } \\
\text { - Categoria de afixação do clítico } & \text { Flexão (PCl/PE) } & \text { Verbo (PB) }
\end{array}
$$$$
\text { -Domínio da restrição }
$$

Vimos que as Cartas Brasileiras, bem como outros documentos da mesma época, instanciam umas realizações contraditórias no que diz respeito a esses parâmetros, situação típica da competição de gramáticas. A restrição de primeira posição não é sempre ativa, e a categoria de afixação do clítico varia. Quanto ao domínio da restrição de primeira posição, parâmetro cuja fixação é menos facilmente detectável nos textos, veremos na próxima seção que a 
competição PCl/PE aparece claramente nos textos brasileiros do século 19 quando se observa a dinâmica da mudança.

\section{A dinâmica da mudança}

O Corpus das Cartas Brasileiras (CARNEIRO, 2005)

O corpus é formado por cartas escritas entre 1809 e 1904 por brasileiros cultos e não cultos nascidos entre 1724 e 1880 (CARNEIRO, 2005). ${ }^{12}$

A forma de datação dos dados se fez de duas perspectivas: por nascimento dos autores e por data de escrita/produção dos textos. A razão para considerar os dados sob pontos de referência temporais distintos, isto é, por data de nascimento dos autores, além da data em que os textos foram escritos, como comumente se faz nos estudos sobre mudança, justifica-se pelo conceito de gramática assumido neste trabalho. O objetivo é acompanhar a dinâmica da mudança gramatical, considerada como resultado de alterações paramétricas no processo de aquisição da língua materna. Paixão de Souza (2004) mostra que as curvas de mudança obtidas com base nas datas de nascimento dos autores do Corpus Tycho Brahe são mais regulares que aquelas baseadas na data de produção dos textos. Todavia, em se tratando de cartas datadas, alguns problemas apontados por Paixão de Sousa - como a própria dificuldade de datar os textos - desaparecem. Por outro lado, uma vez que a escrita do século 19 no Brasil traz uma forte diglossia, resultante da influência da norma europeia que, por sua vez, ainda está instável, interessa também considerar os documentos sob o ângulo da sua data de produção.

Uma outra questão relativa ao uso de cartas é o reagrupamento dos dados, que aqui se faz em períodos de 50 anos. Seguimos Carneiro (2005), que procedeu da seguinte maneira: por data de nascimento dos remetentes, $\underline{1775}$ corresponde ao período $1724^{13}-1799 ; 1825$ a $1800-1850$, e 1875 a $1851-1880 .{ }^{14}$ Por data de produção, 1825 corresponde a cartas escritas entre 1809-1850; 1875 a cartas escritas entre 1851-1875 e 1900 a cartas escritas entre $1876-1904 .{ }^{15}$

\section{A competição de gramáticas no Corpus das Cartas Brasileiras}

Como descrito na Seção I, observamos nas Cartas Brasileiras uma variação ausente das gramáticas estáveis, parecendo corresponder à fixação contraditória dos parâmetros definidos anteriormente: 
- ênclise/próclise no início absoluto de frase, que corresponde à presença/ausência de restrição de clítico em primeira posição, em (41b), além dos exemplos em (1).

(41) a. Peço-lhe que emende a mão| quanto á escripta, por que lembrame que a sua letra ja| foi clara, e boa.carta 17 (CARNEIRO, 2005, p. 114).

b. Nos dê suas| noticias. carta 463 (CARNEIRO, 2005, p. 146).

- clítico afixado ao verbo temático (42a) ou ao verbo auxiliar nas locuções verbais (42b), o que corresponde à ausência/presença de movimento do clítico para a forma finita.

(42) a. Não te-|nho lhe escripto supondo ja| se ter regressado para o Regalo,| e Camuciatá onde devo mandar| Potamio visital-o, a Baronesa e os| Primos. carta 433. (CARNEIRO, 2005, p. 188).

b. Os insuccessos constantes em| todas as minhas pretensões| tem-me creado uma situa=|cão que facilmente comprehen=|derá quanto me é penosa.| carta 239 (CARNEIRO, 2005, p. 191).

Além disso, observamos nesses documentos construções que não são produzidas por nenhuma das três gramáticas descritas acima: trata-se da ênclise nos contextos de próclise obrigatória do PCl e do PE (orações negativas, ${ }^{16}$ exemplos 43a,b, orações subordinadas, ${ }^{17}$ exemplos $43 \mathrm{c}-\mathrm{d}$ ):

(43) a. N. B Elle foi SubDelegado, Dele|gado <muitas vezes $>$ Juiz Municipal, Capitam e| Tenente Coronel o mais não lembrame| Intendente| carta 472 (CARNEIRO, 2005, p. 162).

b. Consta que os adversarios estão pro-(cedendo a apuração da eleição d'essa[...]| em Caxoeira, para tambem serem [di]-| plomados, como os nossos amigos. Nen-|hum só adversario apresentou-se hoje| na apuração que procedeo-se aqui, e| nem tão pouco prottestarão, pelo que| tanto melhor foi para nós. carta 366 (CARNEIRO, 2005, p.162).

c. O Nabuco no seo| Ministerio faltou a promessa que fez| me: o mesmo acconteceo-me com| o Sr. Rego Barros. carta 30 (CARNEIRO, 2005, p.164). 
d. Recebi hontem pelas 2 horas da tarde vossas| estimadas lettras vindas por Francisco o-| qual entregou-me tudo quanto vossa| paternal bondade nos mandou, de tudo| muito vos agradecemos, e. altamente nos| regosijamos por vosso bem estar cuja| continuação almejamos de todo coração.| carta 117 (CARNEIRO, 2005, p.164).

Note-se que não esperamos também que a gramática do PB produza essas frases uma vez que são contraditórias com a ausência de restrição do clítico em primeira posição que caracteriza essa gramática.

Os dois primeiros casos caracterizam claramente o que $\operatorname{Kroch}(1994,2001)$ chama Competição de Gramáticas. O terceiro, a emergência de fenômenos produzidos por nenhuma das gramáticas em presença, é pouco discutido na literatura gerativista sobre mudança, mas é típico de línguas em contato. Emergem novas construções, ausentes de cada um dos sistemas em presença. Podem ser descritas como generalizações feitas pelos falantes a partir da segunda língua que eles adquirem imperfeitamente. No caso dos brasileiros escrevendo no século 19 e tendo como referência o padrão europeu da época, a generalização parece ser que a ênclise é a forma prestigiada, independentemente do contexto. Alternativamente, podemos pensar que esses falantes, cujo vernacular é, por hipótese, essencialmente proclítico, retiram do seu contato com o PE a informação de que existe variação. Entretanto, seu domínio da variante portuguesa não chega a ser suficiente para que consigam adquirir as regras que governam a distribuição da ênclise e da próclise.

Como afirmado por Kroch (2001), a competição de gramáticas é diacronicamente instável e uma das gramáticas acaba ganhando. Na próxima seção, observaremos a dinâmica da competição entre as três gramáticas definidas acima.

\subsection{A competição PCl/PE: Os contextos de variação ênclise/próclise}

A evolução ao longo do século 19 da colocação de clíticos nas orações com o verbo em segunda posição (V2) que, no PCl, correspondem aos contextos de variação I mostra que a ênclise se torna cada vez mais frequente nos textos brasileiros de 1825 em diante. A figura 1 ilustra esse ponto com base nos dados dos corpora de Pagotto (1992) ${ }^{18}$ e Carneiro (2005). ${ }^{19}$ 


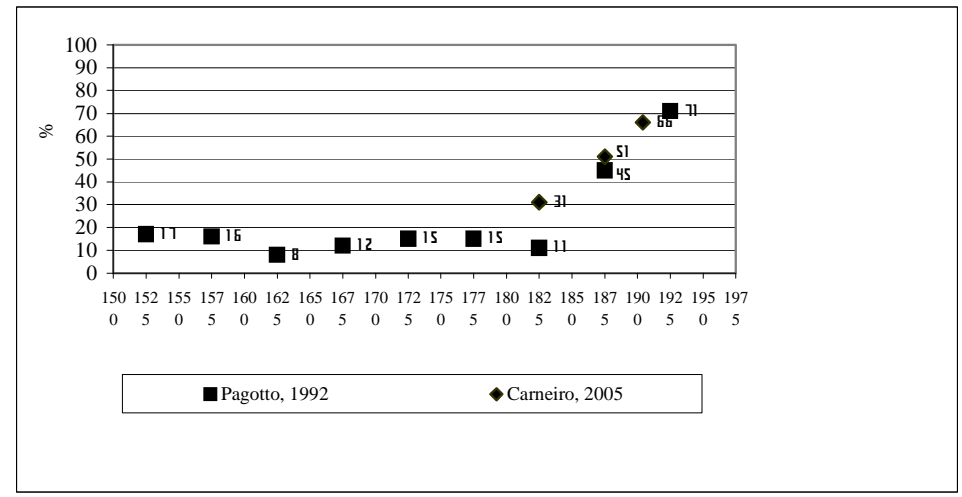

FIGURA 1 - Evolução da ênclise em sentenças V2 em contextos variáveis em textos escritos entre 1525 e 1925 (PAGOTTO, 1992; CARNEIRO, 2005) por data de produção dos textos.

A figura 2, que compara a evolução da ênclise nos textos brasileiros e a mudança afetando a colocação de clíticos no português europeu - com base no estudo dos textos do Corpus Tycho Brahe (GALVES et al., 2005a) - evidencia a influência da segunda sobre a primeira.

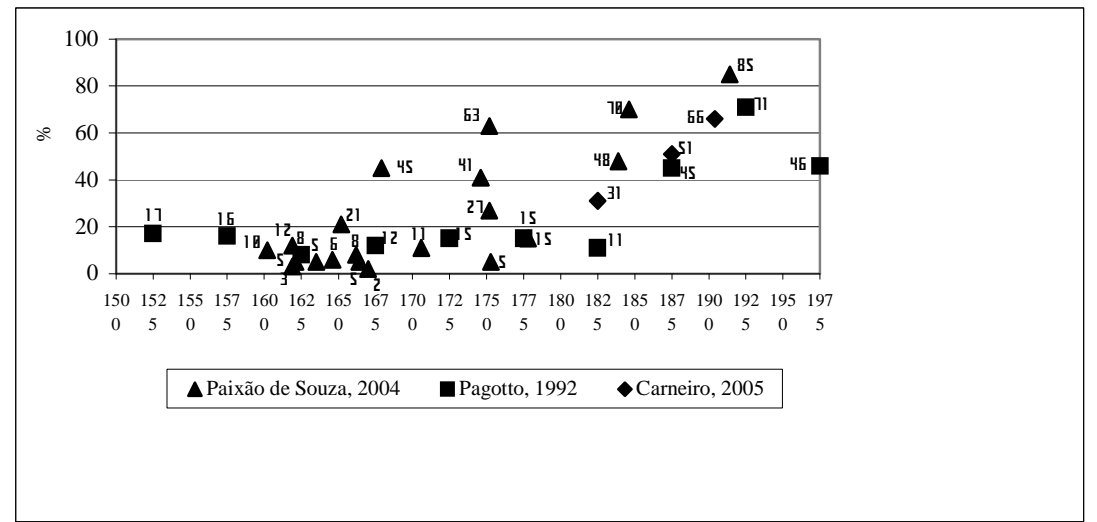

FIGURA 2 - A evolução da ênclise em orações V2 não dependentes (Corpus Tycho Brahe, PAGOTTO, 1992 e CARNEIRO, 2005, por data de produção dos textos).

Vemos que nos textos brasileiros a ênclise demora mais a se afirmar nos contextos V2 considerados. Só vai saindo da casa dos $10 \%$ em 1825, quando os 
textos portugueses já vão para 50\%. Na virada do século, o texto português já tem $85 \%$ de ênclises, e os brasileiros estão na casa dos 70 . Esse gráfico também traz um fato essencial, ao qual voltaremos mais abaixo, a regressão da ênclise no português brasileiro durante o século 20.

A figura 2 se baseia em datas de produção dos documentos, tanto para os corpora brasileiros quanto para o corpus português. Na figura 3, a seguir, vemos de novo a contraposição da evolução da ênclise em contextos de variação I no Corpus Tycho Brahe e nos Corpora brasileiros, mas agora os dados dos autores portugueses são organizados com base na data de nascimento dos autores. $^{20}$

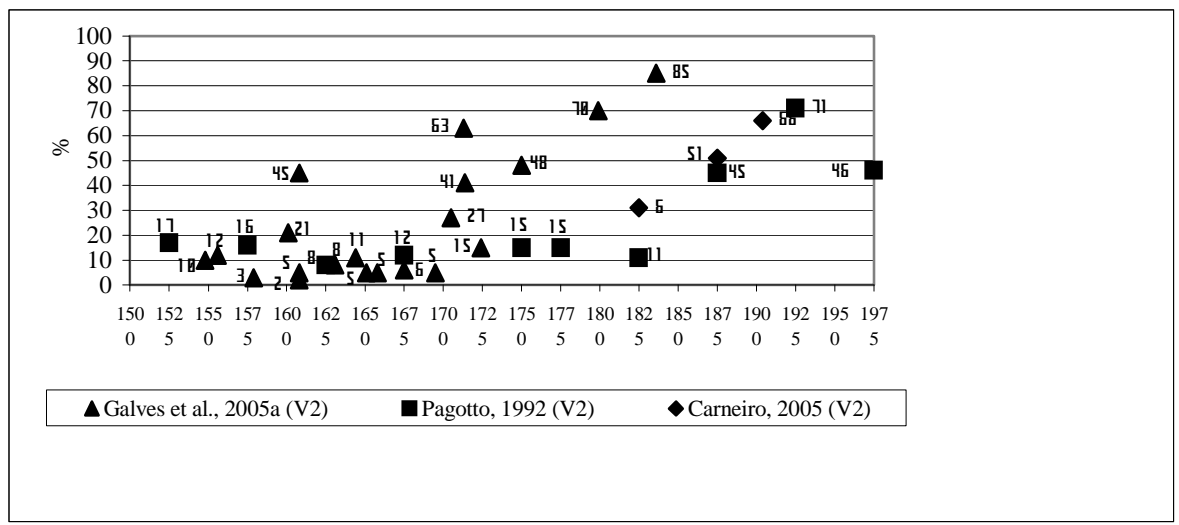

FIGURA 3 - A evolução da ênclise em orações V2 não dependentes (GALVES et al. 2005a, por data de nascimento dos autores e PAGOTTO, 1992 e CARNEIRO, 2005, por data de produção dos textos).

Nessa figura, observamos um notável paralelismo ao longo do tempo entre a evolução das frequências da ênclise no Brasil e em Portugal. O intervalo de tempo entre as duas curvas se mantém de maneira constante num valor de aproximadamente 100 anos, ou seja, podemos dizer que, ao escrever suas cartas, os brasileiros vão se pautando nos valores da variação que se dava na geração portuguesa nascida 100 anos antes. Esse notável paralelismo aponta para a influência da mudança em Portugal, cada vez mais visível a cada geração, sobre a escrita dos brasileiros, independentemente da sua própria data de nascimento (temos a cada ponto remetentes de idades diferentes). 
Note-se enfim que é esse paralelismo que nos autoriza em falar de competição entre PCl e PE nos textos novecentistas brasileiros. Apesar dessa não ser a competição que corresponde aos próprios rumos do português no Brasil, ela está claramente instanciada nos textos dessa época. No século 20, porém, uma nova competição, agora entre PB e PE, fará reverter essa tendência, como vemos na queda da curva entre 1925 e 1975 nos dados de Pagotto (1992) e (CARNEIRO, 2005).

\subsection{A competição PCl/PB: próclise em V1 e colocação nos grupos verbais}

\section{Próclise em V1}

Nas Cartas Brasileiras, observamos uma variação ausente das gramáticas estáveis, parecendo corresponder à fixação contraditória dos parâmetros definidos anteriormente. Trata-se da ênclise/próclise no início absoluto de frase, que corresponde à presença/ausência de restrição de clítico em primeira posição (cf. exemplos em (1) e (41a e 41b).

A próclise em V1 é o fenômeno mais saliente da inovação brasileira na colocação de clíticos. No século 19, aparece muito timidamente nos textos. O corpus mais literário de Pagotto (1992) não tem nenhum caso, também não foi encontrado em Lobo (2001). No corpus estudado por Pagotto e Duarte (2006), de cartas escritas por um casal de avós aos seus netos, encontram-se ocorrências nas cartas da avó, mas não nas do avô, um homem culto. Eis alguns exemplos:

(44) Os abraça Sua Dindinha e Amiga Bárbara (Carta 36). (PAGOTTO e DUARTE, 2006, p.77).

No corpus de Carneiro (2005), encontram-se várias ocorrências, essencialmente nos remetentes menos escolarizados. Para localizar esses dados no tempo, é interessante considerar os dois pontos de referência evocados acima: as datas de produção dos textos e as datas de nascimento dos autores. Do ponto de vista da produção, encontramos próclise em V1 no último grupo de cartas, aquelas escritas entre 1875 e 1925 (cf. FIG. 4). 


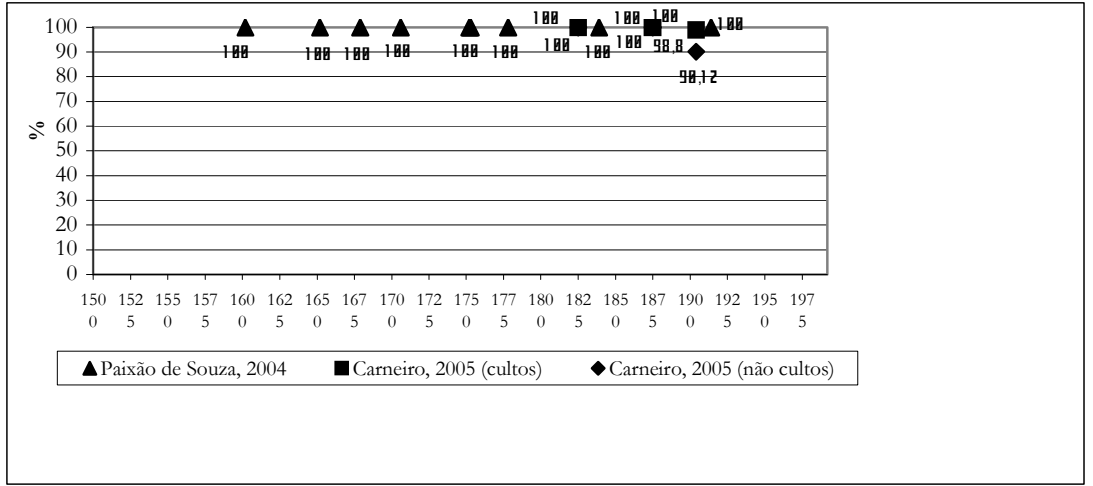

FIGURA 4 - A evolução da colocação dos clíticos, por data de produção dos textos (Corpus Tycho Brahe; CARNEIRO, 2005: pessoas escolarizadas versus não escolarizadas).

Do ponto de vista da geração biológica, porém, descobrimos que os autores dessa cartas são do segundo grupo, nascidos entre 1825 e 1875 (cf. FIG. 5).

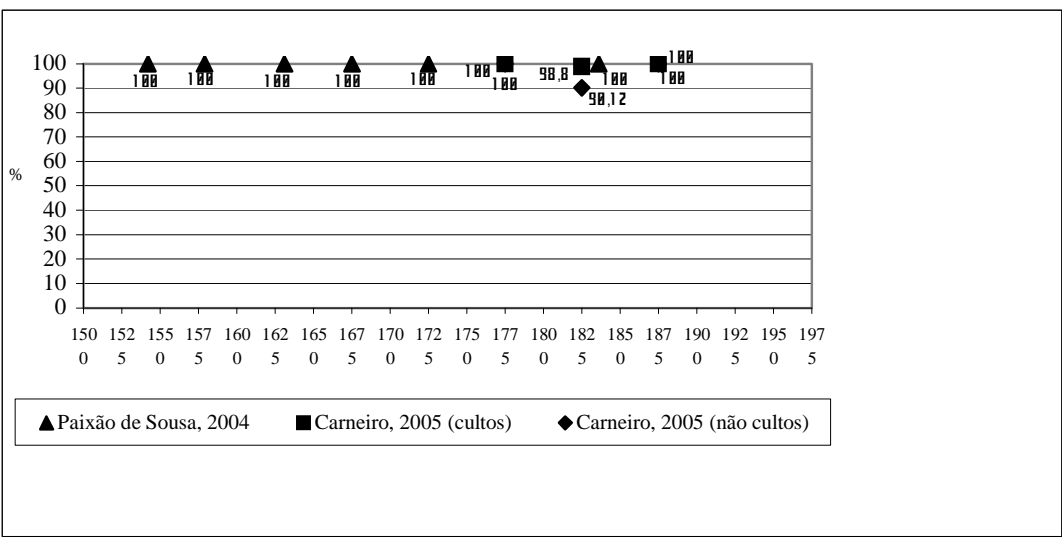

FIGURA 5 - A evolução da próclise em V1 por data de nascimento (Corpus Tycho Brahe; CARNEIRO, 2005: pessoas escolarizadas versus não escolarizadas).

Uma possível interpretação desse fato é que os mais jovens dos remetentes sofrem uma forte influência do aumento da ênclise, que acompanha a consolidação da mudança no PE, bloqueando a pressão do vernacular que não tem mais restrição de clítico em primeira posição. A figura 6 mostra a evolução da próclise em V1 e da ênclise em V2 no mesmo gráfico. Podemos interpretar 
o movimento de avanço e recuo da primeira como, num primeiro tempo, o reflexo da competição entre PCl e PB, o PB começando a se manifestar nos textos, e, num segundo tempo, a instanciação da competição entre PB e PE, que, provisoriamente, bloqueia o avanço do PB nos textos, em função da influência crescente nos contextos V2 nesse período.

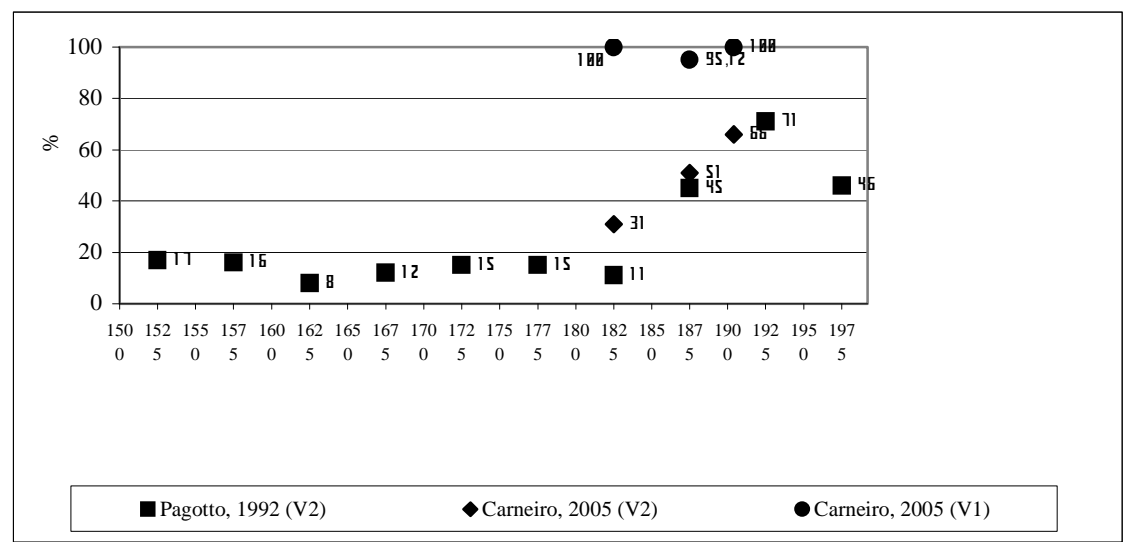

FIGURA 6 - A evolução da colocação dos clíticos em sentenças V1 (CARNEIRO, 2005 - por data de nascimento dos autores) e em sentenças não dependentes V2(PAGOTTO, 1992; CARNEIRO, 2005, por data de produção dos textos).

\section{A colocação dos clíticos em grupos verbais}

Observemos agora a posição do clítico nos grupos verbais. Como vimos anteriormente, existem três casos: o movimento não ambíguo do clítico para o auxiliar, a afixação não ambígua do clítico à forma não finita, e enfim, sequências ambíguas, compatíveis com a afixação do clítico tanto ao auxiliar (em ênclise) quanto ao verbo não finito (em próclise) (cf. 46b). A figura 7 mostra a evolução das variantes não ambíguas ao longo do tempo. No marcador do tipo quadrado, vê-se o corpus de Pagotto (1992), nos círculos, o de Carneiro (2005) relativo aos escolarizados e, no losango, o corpus de Carneiro relativo aos não escolarizados. $^{21}$ 


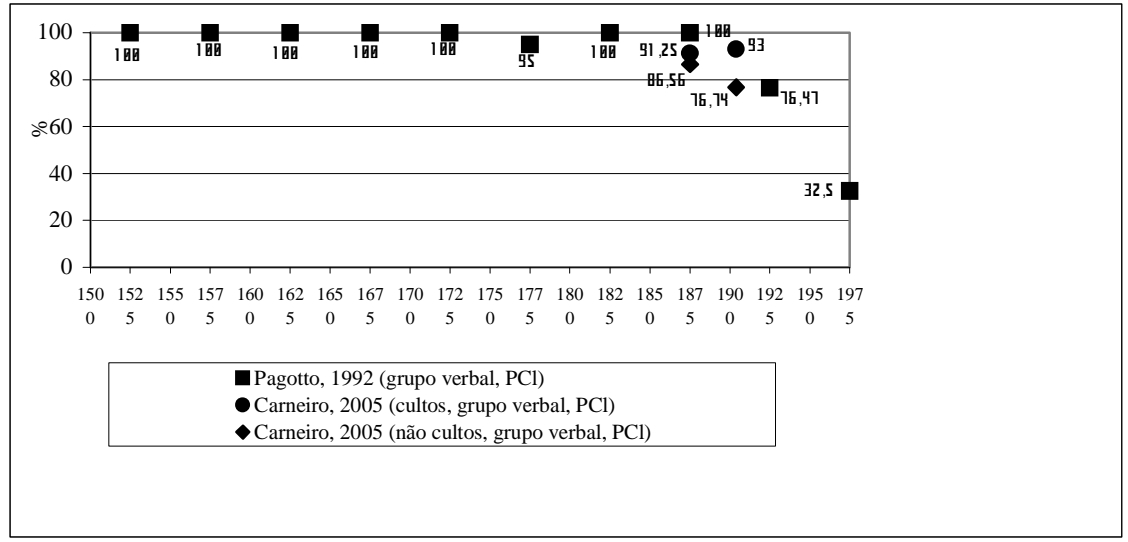

FIGURA 7 - A evolução da colocação dos clíticos em grupos verbais: percentual de estruturas não ambíguas por data de produção (PAGOTTO, 1992, CARNEIRO, 2005: pessoas escolarizadas versus pessoas não escolarizadas)

De novo observamos coincidência entre os dois corpora. Vemos também, novamente, que os não escolarizados, na virada do século, estão mais adiantados em relação a essa mudança do que os escolarizados. O corpus literário de Pagotto levará mais 25 anos para chegar aos mesmos valores.

\section{Conclusão}

Os gráficos apresentados evidenciam que a competição entre três gramáticas nos textos pode ser representada por uma articulação de competições entre duas gramáticas, ocorrendo simultaneamente ou sucessivamente. No que diz respeito ao século 19, podemos sintetizá-las no seguinte quadro:

- PCl/PB: Próclise/Ênclise em sentenças V1.

- PCl/PE: Ênclise/Próclise em sentenças não dependentes V2.

- PCl/PB: Posição do clítico (V/INFL) em grupos verbais.

- PB/PE: Ênclise/Próclise em sentenças V1.

Tomando o PCl como sendo a gramática inicial cronologicamente, vimos que, no que diz respeito à variação ênclise/próclise, ele entra em competição tanto 
com o PB quanto com o PE, com resultados contraditórios, uma vez que o PB vai no sentido da próclise e o PE no sentido da ênclise. Outro fenômeno envolvido na competição $\mathrm{PCl} / \mathrm{PB}$ é a posição do clítico nos grupos verbais.

Vimos também (cf. FIG. 5) uma reversão da tendência nas construções V1. Enquanto a segunda geração da Cartas Brasileiras inicia um processo no sentido da próclise em posição inicial, típica do PB, a terceira geração volta atrás. Podemos interpretar esse movimento oposto como uma competição entre o PB e o PE, uma vez que, no mesmo período, esse favorece cada vez mais a ênclise nas construções V2. Note-se que, contrariamente ao que acontece quando só duas gramáticas estão em competição, em que uma delas, segundo o modelo de Kroch, se afirma cada vez mais, a interação de três gramáticas parece ser potencialmente geradora de movimentos opostos. É o que vimos na progressão do clítico em início absoluto de frase no século 19, e é o que veremos também, no século 20 a partir de 1925, no decréscimo da ênclise nas orações V2 (cf. os dados de Pagotto (1992) na figura 6), reflexo da competição entre PB e PE.

\section{Notas}

${ }^{1}$ Este trabalho é a versão revisada da comunicação apresentada no 9th Diachronic Generative Syntax Conference, em Trieste, Itália, em junho de 2006.

${ }^{2}$ As marcações (ok) e (*) indicam, respectivamente, padrões possíveis e não possíveis de colocação de clíticos, no português clássico (PCl), português europeu moderno (PE) e português brasileiro (PB).

${ }^{3}$ Para a noção de 'mudança fracassada', cf. Postma (a sair).

${ }^{4}$ Uma notável exceção se encontra nos Sermões de Vieira. Para uma interpretação, cf. Galves (2003) e Galves et al. (2005a). Ver também a Seção 2.2.

${ }^{5}$ Fazemos abstração aqui da tendência na língua coloquial, recentemente descrita em alguns trabalhos (cf. entre outros DUARTE; MATTOS; FARIA, 1995), em usar ênclise em contextos até então de próclise categórica. Parece se tratar da implementação de uma nova gramática da colocação de clíticos no português europeu falado, que foge aos limites deste trabalho.

${ }^{6}$ Não consideraremos também a variação próclise/ ênclise em subordinadas, que também existe, ainda que de maneira marginal, em português clássico (cf. ARAÚJO LOPES, 2010), bem como em outras línguas ibéricas conservadoras, como o asturiano (cf. FERNANDEZ-RUBIERA, 2009). Para uma descrição e análise deste fenômeno em português europeu moderno, cf. Vigário e Frota (1998). 
${ }^{7}$ Ou seja, a projeção máxima de Comp (Complementador).

${ }^{8}$ Uma análise muito semelhante é proposta por Barbosa (2008). A diferença entre as duas abordagens reside na formulação da regra que abaixa o clítico para o verbo, bem como na questão da posição do sujeito.

${ }^{9}$ Trabalhando no quadro teórico da Morfologia distribuída, as autoras argumentam ainda que a regra responsável pela afixação do clítico ao verbo é a regra "Abaixamento" (Lowering) que, apesar de ser uma regra do componente morfológico, ainda tem acesso à estrutura sintática. Isso contrasta com o $\mathrm{PCl}$ em que a afixação do clítico se dá depois da construção dos domínios prosódicos. No modelo da Morfologia distribuída, a regra que se aplica nesse nível é chamada de "Inversão prosódica".

${ }^{10}$ Conforme mostrado na edição utilizada pelas autoras: COELHO, Paulo. $O$ Alquimista. 1990. 56. ed. Rio de Janeiro: Rocco. 248p e COELHO, Paulo. O Alquimista. 1999. 11a reimpressão. Lisboa: Pergaminho. 224p.

${ }^{11}$ Nossa proposta é que o comportamento diferente dos clíticos em PE e PB deriva da interação de duas propriedades diferentes: a) a categoria à qual os clíticos se adjungem sintaticamente: os clíticos do PE se adjungem a Infl e os clíticos do PB se adjungem a V. b) a restrição fonológica que obriga os clíticos a estarem numa posição não inicial com respeito a alguma fronteira: ativa no PE, inativa no PB.

${ }^{12}$ Trata-se de uma edição semidiplomática e fac-similada de 500 cartas particulares, depositadas no Arquivo do Instituto Histórico e Geográfico da Bahia e no Arquivo do Barão de Jeremoabo. Na tese, a autora divide as cartas em duas amostras: 1) cartas escritas por brasileiros cultos nascidos entre fins do século XIX e brasileiros cultos nascidos até o terceiro quartel do século 19 e 2) cartas escritas por brasileiros semicultos e não cultos nascidos/radicados no interior da Bahia no século 19. Os dados empíricos são compostos por 3.196 dados sobre colocação de clíticos.

${ }^{13}$ Cf. detalhamentos em Carneiro (2005, capítulo 2).

${ }^{14}$ Data de nascimento do remetente mais jovem (13 anos), que escreve a seu padrinho e parente, o barão de Jeremoabo.

${ }^{15}$ Consideram-se as cartas entre 1900-1904 como sendo cartas do século 19, uma vez que foram produzidas por indivíduos que vinham escrevendo no século 19.

${ }^{16}$ Há menções na literatura do uso da ênclise em orações negativas por parte de crianças adquirindo o PE como língua materna (cf. DUARTE et al., 1995). Assumimos aqui que essa colocação não é produzida pela gramática adulta. 
${ }^{17}$ Note-se que, segundo Vigário e Frota (1998), a ênclise em subordinadas no PE depende da presença de uma fronteira de frase entoacional entre o gatilho da próclise (a conjunção) e o verbo e, portanto, da ocorrência de algum sintagma topicalizado ou frase parentética entre a conjunção e o verbo. Nos exemplos c, d não é o caso, já que o verbo está adjacente à conjunção.

${ }^{18}$ Cf. Pagotto (1992, p.64-66). Nesse estudo, o autor investigou o percurso diacrônico dos clíticos pronominais em português em cartas e documentos oficiais, escritos no Brasil entre 1600 e 1975, encontrando 1.436 dados. Embora seja um corpus misto e não uniforme, principalmente do ponto de vista tipológico, há garantias da nacionalidade de autores que escrevem a partir do século 19.

${ }^{19}$ Vale notar a coincidência de resultados obtidos a partir de corpora completamente distintos.

${ }^{20}$ Essa é a metodologia seguida nos trabalhos baseados no Projeto Corpus Histórico do Português Tycho Brahe (www.tycho.iel.unicamp.br), em particular em Galves et al. (2005a).

${ }^{21}$ A razão de haver somente dois pontos para cada tipo de remetente se deve ao fato de, no primeiro período, os dados serem muito escassos.

\section{Referências}

ARAÚJO LOPES, Ana Luiza. (2010) A ênclise em orações dependentes na história do português europeu (séc. 16 a 19). 2010. Dissertação (Mestrado) - Universidade Estadual de Campinas, Campinas, 2010.

BARBOSA, Pilar. Deslocação local, cliticização e Spell Out cíclico. Diacrítica, v.22, n. 1, 2008.

CARNEIRO, Zenaide de Oliveira Novais. Cartas brasileiras: um estudo linguísticofilológico. 2005. Tese (Doutorado) - Unicamp, 2005.

CHOMSKY, Noam. Knowledge of language: Its nature, origin e use. New York, Praeger, 1986.

CHOMSKY, Noam. Derivation by phase. MIT Occasional papers in Linguistics, v. 16, 1999.

CORPUS HISTORICO DO PORTUGUES TYCHO BRAHE - 2 $2^{\mathrm{a}}$ versão, 2006. http://www.tycho.iel.unicamp.br/ tycho/

DUARTE, Inês; MATOS, Gabriela; HUB FARIA, Isabel. Specificity of European Portuguese Clitics in Romance. In: FARIA, Isabel; FREITAS, Maria João (Ed.). Studies on the Acquisition of Portuguese. Lisboa: APL/Edições Colibri, 1995. p. 129-154. 
FERNANDEZ-RUBIERA, Francisco. Clitics at the edge: clitic placement in western Iberian Romance Languages. 2009. Tese (Doutorado) - Georgetown University.

GALVES, Charlotte. Sintaxe e estilo: a colocação de clíticos nos sermões do Pe Antonio Vieira. In: ALKMIM, Tânia; ALBANO, Eleonora; HADLER, Maria Irma; POSSENTI, Sírio (Org.). Saudades da língua. S.Paulo: Companhia das Letras, 2003.

GALVES, Charlotte; SANDALO, Filomena. Clitic-Placement in European Portuguese e the Syntax-Phonology Interface. In: CASTRO, Ana; FERREIRA, Marcelo; HACQUARD, V.; SALANOVA, Andrés Pablo (Ed.). Romance Op. 47, Collected papers on romance syntax, MIT Working Papers in Linguistics 47, p.115-128, 2004.

GALVES, Charlotte; SANDALO, Filomena. From Intonational Phrase to Syntactic Phase: the grammaticalization of enclisis in the history of Portuguese. Unicamp, Campinas, 2009. Manuscrito.

GALVES, Charlotte; BRITTO, Helena; PAIXÃO DE SOUSA, Maria Clara. The Change in Clitic Placement from Classical to Modern European Portuguese: Results from the Tycho Brahe Corpus. Journal of Portuguese Linguistics, v. 4, n. 1, HUALDE, José Ignacio (Ed.). Special Issue on Variation e Change in the Iberian Languages: the Peninsula e beyond , p.39-67, 2005a.

GALVES, Charlotte, RIBEIRO, Ilza; TORRES MORAES, Maria Aparecida. Syntax e morphology in the placement of clitics in European e Brazilian Portuguese. Journal of Portuguese Linguistics, v. 4, n. 2. PERES, João; KATO, Mary (Ed.). Studies in the comparative syntax of European and Brazilian Portuguese, p. 143-177, 2005b.

KROCH, Anthony. Morpho-syntactic variation. In: BEALS, Kenneth et al. (Ed.). Papers from the 30th Regional Meeting of the Chicago Linguistics Society: Parasession on Variation e Linguistic Theory, v. 2, p. 180-201, 1994.

KROCH, Anthony. Syntactic change. In: BALTIN, Mark; COLLINS, Chris (Ed.). The Handbook of Contemporary Syntactic Theory. Oxford, Blackwell Publishers, 2001. p. 699-729.

LIGHTFOOT, David. The development of Language, Acquisition, Change and Evolution. Oxford: Blackwell Publishers, 1999.

LOBO, Tânia. Para uma sociolinguística histórica do português do Brasil: edição filológica e análise linguística de cartas particulares do recôncavo da Bahia, século XIX. 2001. Tese (Doutorado) - Universidade de São Paulo/FFLCH, 2001.

MARTINS, Antonio. Competição de gramáticas do português na escrita catarinense dos séculos 19 e 20. 2009. Tese (Doutorado) - Universidade Federal de Santa Catarina, 2009. 
PAGOTTO, Emílio. A posição dos clíticos em português: um estudo diacrônico. 1992. Dissertação (Mestrado) - Unicamp, Campinas, 1992.

PAGOTTO, Emílio; DUARTE, Maria Eugênia. Gênero e norma, avós e netos, classes e clíticos no final do séc. XIX. In: LOPES, Célia Regina dos Santos (Org.). (2005) A norma brasileira em construção. Fatos linguisticos em cartas pessoais do século 19. Rio de Janeiro: FAPERJ/UFRJ, 2006.

PAIXÃO DE SOUSA, Maria Clara. Língua barroca, sintaxe e história do português nos seiscentos. 2004. Tese (Doutorado) - Unicamp, Campinas, 2004.

POSTMA, Gertjan. The Impact of Failed Changes. In: BREITBARTH, Anne; LUCAS, Chris; WATTS, Sheila; WILLIS, David (Ed.). Continuity and Change in Grammar. Benjamins. No prelo.

ROBERTS, Ian. Diachronic Syntax. Oxford: Oxford University Press, 2007.

VIGÁRIO, M., FROTA, S. Between Syntax and Phonology: On Phrasal Weight Effects in European Portuguese. Comunicação ao 8TH COLLOQUIUM ON GENERATIVE GRAMMAR, Palmela, Portugal, 1998. 